Peter S. Yeh

\title{
Spontaneous antenatal uterine rupture 3 years after laparoscopic myomectomy
}

Received: 1 March 2005 / Published online: 26 August 2005

(C) Springer-Verlag Berlin / Heidelberg 2005

\begin{abstract}
A 31-year-old primigravid woman with a history of intramural laparoscopic myomectomy presented with acute abdominal pain at 32 weeks of gestation. Ultrasound revealed a fundal uterine rupture with herniation of the intact amniotic membranes together with a foetal limb outside the uterine cavity. An emergency caesarean section was carried out, and a live female neonate weighing $1,950 \mathrm{~g}$ was delivered.
\end{abstract}

Keywords Laparoscopy $\cdot$ Myoma $\cdot$ Myomectomy Uterine rupture

A 31-year-old woman presented at 32 weeks' gestation in her first pregnancy with abdominal pain for 1 day. The pain was dull and constricting all over the abdomen, with no relieving or exacerbating factors. She had intermittently had a similar type of pain but in a milder form for many weeks. Her antenatal course had been uneventful until presentation. In her past history, she had undergone laparoscopic myomectomy at the same hospital 3 years previously for an intramural fundal myoma.

On reviewing the records of her previous laparoscopic myomectomy, a fundal myoma measuring 2.3 by $1.6 \mathrm{~cm}$ had been removed, the uterine wound sutured, and an absorbable adhesion barrier Interceed placed over the wound.

On examination, the patient appeared to be in a lot of constant pain and was unable to walk unaided; she required a wheelchair. Her temperature was $37.6^{\circ} \mathrm{C}$, pulse was $80 / \mathrm{min}$, and blood pressure $130 / 70 \mathrm{mmHg}$. The white cell count was normal at $10 \times 10^{9} / 1$. The uterus was irritable and tender. The abdomen showed rebound tenderness and guarding. The cervix was long and

P. S. Yeh

Department of Obstetrics and Gynaecology,

Bedford Hospital NHS Trust, Bedford, UK

E-mail: yehpeter@hotmail.com

Fax: + 44-1954-710601 closed; it was not dilated or effaced. The cardiotocogram was normal, with many foetal heartbeat accelerations and no decelerations.

On ultrasound examination, a uterine fundal rupture was seen. There was herniation of amniotic membranes and their contents - a limb - through the uterine fundal defect into the abdominal cavity (Fig. 1).

An emergency caesarean section was carried out. There was no bleeding at the rupture site. The uterus was incised longitudinally and inferiorly from the fundal defect for delivery of the baby. A female neonate weighing $1,950 \mathrm{~g}$ was delivered in good condition with Apgar scores of 9,10 , and 10 at 1,5 , and $10 \mathrm{~min}$, respectively. No blood transfusion was required. The patient made an uneventful postoperative recovery.

\section{Discussion}

Laparoscopic myomectomy is a technique that allows small intramural and subserosal myomas to be managed by endoscopic surgery [1]. It has become popular in the last decade. Compared with laparotomy, laparoscopic myomectomy offers the advantages of reduced postoperative pain, shorter hospital stay, and quicker recovery to normal activity [2].

However, the potential weakness of the hysterotomy scar manifesting as a uterine rupture in the third trimester of pregnancy before labour is being realised [3-5]. This risk exists not only after intramural but also subserosal laparoscopic myomectomies, even when the myoma was superficial [4].

In a retrospective study involving 100 patients, the risk of uterine rupture following laparoscopic myomectomy was estimated as $1 \%(95 \%$ CI $0-5.5 \%) ; 72 \%$ of patients had trials of labour, and of these, $80.6 \%$ delivered vaginally, and there was no uterine rupture during the trials of labour [6].

Of the reported cases in the literature, the gestational window for the gravid uterine rupture following laparoscopic myomectomy was 28-35 weeks; all occurred 

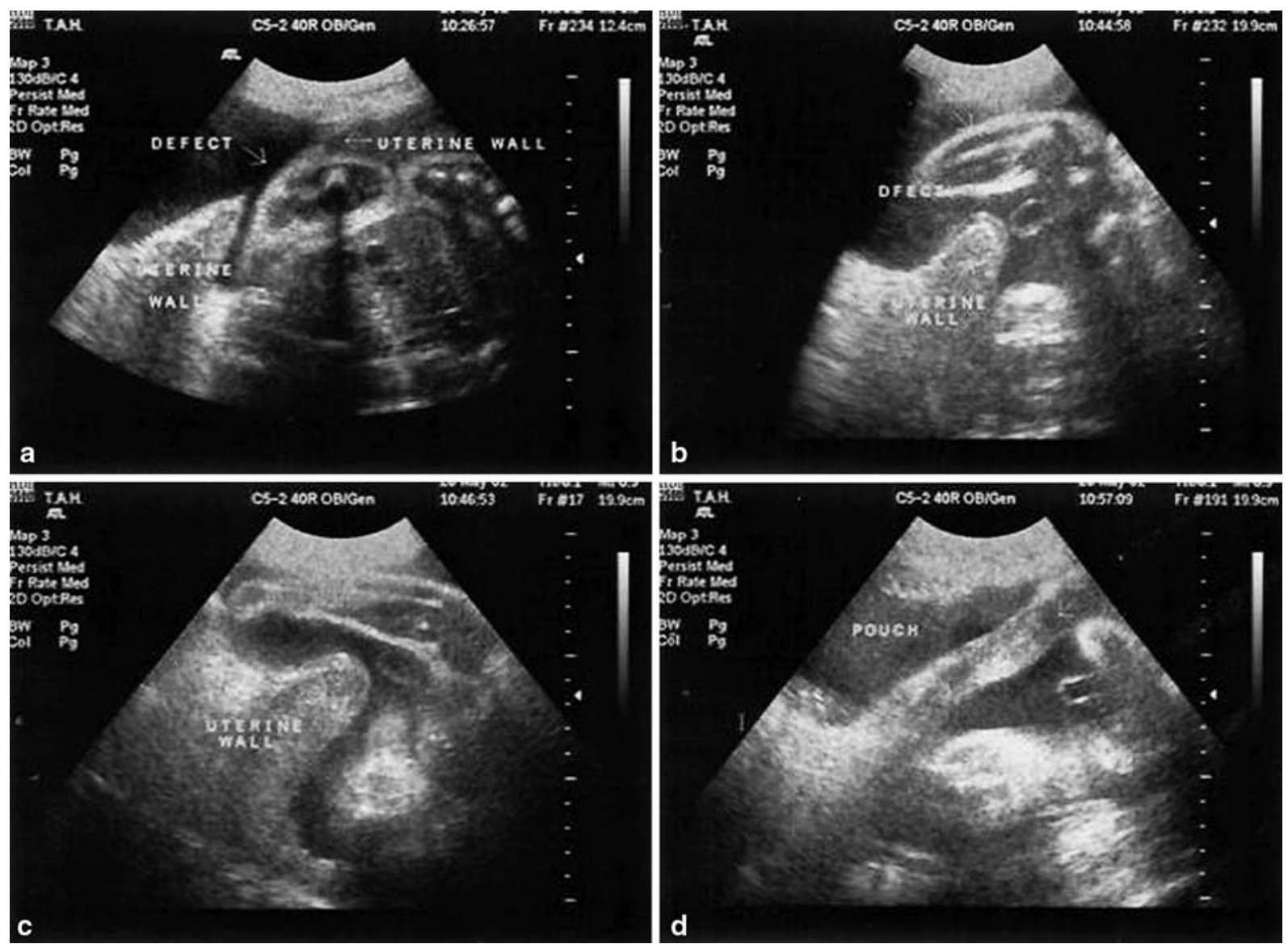

Fig. 1 a-d Ultrasound showing uterine defect or rupture through which amniotic membranes and contents protrude

prelabour. The fetal heartbeat may or may not demonstrate any abnormality [3, 4, 7, 8-11].

It has been hypothesized that uterine rupture after laparoscopic myomectomy is the result of suboptimal healing exacerbated by poor vascularisation of some parts of the uterus such as the fundus in the midline, thus predisposing these sites to weakness [4]. The minimum haemoperitoneum in this case and in other reported cases support this hypothesis [3, 4, 7-11].

Furthermore, it raises the question of ways to prevent or minimise this complication. Dubuisson et al. have suggested that the best way is to make the uterine suture following laparoscopic myomectomy as meticulous as possible [3].

Acknowledgements I am grateful to Mr. R.P. Balfour and Mr. L. Impey for reading the manuscript and for their helpful suggestions.

\section{References}

1. Dubuisson JB, Chapron C (1996) Laparoscopic myomectomy today. A good technique when correctly indicated. Hum Reprod 11:934-935

2. Mais V, Ajossa S, Guerriero S et al (1996) Laparoscopic versus abdominal myomectomy: a prospective, randomised trial to evaluate benefits in early outcome. Am J Obstet Gynecol 174:654-658
3. Dubuisson JB, Chavet X, Chapron C, Gregorakis SS, Morice P (1995) Uterine rupture during pregnancy after laparoscopic myomectomy. Hum Reprod 10:1475-1477

4. Pelosi MA III, Pelosi MA (1997) Spontaneous uterine rupture at thirty-three weeks subsequent to previous superficial laparoscopic myomectomy. Am J Obstet Gynecol 177:15471549

5. Nkemayim DC, Hammadeh ME, Hippach M, Mink D, Schimide W (2000) Uterine rupture in pregnancy subsequent to previous laparoscopic electromyolysis. Arch Gynecol Obstet 264:154-156

6. Dubuisson JB, Fauconnier A, Deffarges JV, Norgaard C, Kreiker G, Chapron C (2000) Pregnancy outcome and deliveries following laparoscopic myomectomy. Hum Reprod 15(4):869-873

7. Lieng M, Istre O, Langebrekke A (2004) Uterine rupture after laparoscopic myomectomy. J Am Assoc Gynecol Laparosc 11(1):92-93

8. Asakura H, Oda T, Tsunoda Y, Matsushima T, Kaseki H, Takeshita T (2004) A case report: change in fetal heart rate pattern on spontaneous uterine rupture at 35 weeks gestation after laparoscopic assisted myomectomy. J Nippon Med Sch 71(1):69-72

9. Nkemayim DC, Hammadeh ME, Hippach M, Mink D, Schmit W (2000) Uterine rupture in pregnancy subsequent to previous laparoscopic electromyolysis. Case report and review of the literature. Arch Gynecol Obstet 264(3):154-156

10. Friedman W, Maier RF, Luttkus A (1996) Uterine rupture after laparoscopic myomectomy. Acta Obstet Gynecol Scand 75:683-684

11. Harris WJ (1992) Uterine dehiscence following laparoscopic myomectomy. Obstet Gynecol 80:545-546 